\title{
1 When defining boundaries for nexus analysis, let the data speak
}

2 Oliver Taherzadeh ${ }^{1 *}$

3 Mike Bithell ${ }^{1}$

4 Keith Richards ${ }^{1}$

$5{ }^{1}$ Department of Geography, University of Cambridge, Downing Place, Cambridge CB2 3EN

6 * Corresponding author: oat24@cam.ac.uk

8 A policy and research agenda has emerged in recent years to understand the interconnected risks 9 natural resource systems face and drive. The so-called 'Food-Energy-Water' (FEW) nexus has 10 served as a focal point for the conceptual, theoretical and empirical development of this agenda. 11 This special issue provides an opportunity to reflect on whether natural resource use, as viewed 12 through the FEW-nexus lens, provides a useful basis for guiding integrated environmental 13 management.

Within this piece, we describe how the partiality of FEW-nexus overlooks major pathways of resource use (i) within the food system and (ii) across the wider burden of human activity. As a result, we argue FEW-centric analysis is more likely to disguise rather than reveal key opportunities for integrated environmental management.

\section{Rethinking critical pathways}

FEW nexus analysis assigns primary importance to interdependent pathways of resource use within the food system: food-energy, energy-water, food-water. Although this adds a new vantage point to assess the environmental impact of food systems, these feedbacks often do not constitute major pathways of resource use (Bijl, et al. 2018; Vivanco, et al. 2018; White, 2018). In China and the United States Vivanco and colleagues found major water and energy footprints within the foodrelated sectors to arise from direct and indirect (i.e. embodied) consumption, not feedbacks between water extraction and energy use (Vivanco, et al. 2018). Indeed, these feedbacks contribute to less than $1 \%$ of total water and energy resource use across all economic output in these nations. Consequently, analysis of FEW nexus linkages alone may provide an insufficiently complete picture for managing resource-related risks within the food system. As a recent editorial in Nature notes: "...the risk is that containing this territory, however loosely, constrains it instead — and that the nexus becomes the focus of the analysis, rather than a natural consequence of studying the supporting problems. ${ }^{1 "}$ 
1 A whole systems approach to environmental management must examine the totality of resource

2 use within the food system. Such an approach can help to identify less complex, but more

3 significant pathways leading to absolute resource use (Vivanco, et al. 2018).

\section{Rethinking critical boundaries}

6 By definition, FEW-centric analysis overlooks competition for water, energy, and land resources for other services (e.g. construction, electronic, and clothing) and priorities (e.g. environmental conservation and urban development). In some cases, non-food resource use poses a more acute environmental burden than food consumption and production (Vivanco, et al. 2018). The construction or renewal of manufactured capital (buildings, infrastructure, machinery, and equipment) is responsible for half of annual global material extraction, underlining the need to extend nexus analysis beyond the food sector (Krausmann, et al. 2017).

A more comprehensive multi-sectoral analysis of 'the nexus' can help inform integrated natural resource management in several ways. First, it can help to identify countries, sectors, and supply chains critical to the promotion of integrated management of water, energy, land, and climate. Despite a growing number of studies on the FEW nexus, we still lack a foundational understanding of these priority areas. Second, multi-sectoral analysis can help identify and evaluate possible rebound effects induced by sustainability measures where income savings or moral licensing shift consumption, and its associated environmental impacts, from target sectors to other production systems (Wood, et al. 2017). Third, nexus analysis undertaken across all aspects of human activity can help to inform more coherent, comprehensive, and transformative pathways for living well within planetary boundaries. The speed, scale, and severity of resource depletion and environmental change requires no less than a systemic approach; it is not clear FEW-nexus analysis provides this.

\section{Where next for the nexus?}

If we accept the need to redraw the boundaries of nexus analysis, to encompass multiple pathways of resource use within coupled human and environmental systems, what is the application of existing FEW-based modelling within this context? The topical focus of nexus-based assessment on FEW interactions undoubtedly limits the application of existing tools and methods of analysis to this end. Most models focus on the manual construction of resource accounts for specific pathways of resource which make their flexible application across multiple sectors, supply chains, and spatial scales impractical. Within this context, national and global resource accounting methods, such as material flow accounting and environmental input-output analysis, offer a promising avenue for broadening the scope and policy utility of nexus-based analysis (Bijl, et al. 2018; Vivanco, et al. 2018; White, et al. 2018). Such methods of analysis offer a more comprehensive account of 
resource use across all aspects of human activity, enabling identification of important sectoral and spatial scales of nexus management. This allows for a global view of the network of human activity and the way in which interlinkages and trade flows between nations redistribute the environmental burdens of production and consumption. Such a re-configuration of nexus analysis does not demand the development of entirely new areas of scholarship, but simply better linkage of existing data, models and insights within natural resource accounting research.

8 In contrast to other commentators, we do not question the principle need for nexus-style 9 assessment. As development begins to outstrip the limited capacities of multiple environmental systems (water, land, climate, ecosystems and beyond), integrated appraisal of policy measures appears increasingly necessary; agendas such as the UN Sustainable Development Goals demand this. Instead, we argue FEW-centric analysis fails to capture fully the many drivers of resource use within production and consumption systems. While effective management of the FEW linkages might promote sustainable allocation of natural resources, it does not necessarily guarantee it. As a rule of thumb, boundaries of nexus analysis and governance should be informed by a comprehensive understanding of the total environmental burden of human activity as it emerges from analysis of the data. By contrast current FEW analysis tries to set these boundaries a priori. Only when we zoom out from the FEW nexus can we begin to identify the opportunities for joined-up thinking in our complex and changing world.

\section{References} Different spatial scales for water, food and energy. Global Environmental Change, 48, 22-31. https://doi.org/10.1016/j.gloenvcha.2017.11.005

Krausmann, F., Wiedenhofer, D., Lauk, C., Haas, W., Tanikawa, H., Fishman, T., Miatto, A., Schandl, H., Haberl, H., 2017. Global socioeconomic material stocks rise 23-fold over the 20th century and require half of annual resource use. Proc. Natl. Acad. Sci. 114, 1880-1885. https://doi.org/10.1073/pnas.1613773114

Vivanco, D.F., Ranran, W., Sebastiaan, D. \& Hertwich, E. (2018). Unraveling the Nexus: Exploring the Pathways to Combined Resource Use. Journal of Industrial Ecology, $0(0)$. https://doi.org/10.1111/jiec.12733

Wood, R., Moran, D., Stadler, K., Ivanova, D., Steen-Olsen, K., Tisserant, A., \& Hertwich, E. G. (2017). Prioritizing Consumption-Based Carbon Policy Based on the Evaluation of Mitigation Potential Using Input-Output Methods: Prioritizing Consumption-Based Carbon Policies. Journal of Industrial Ecology. https://doi.org/10.1111/jiec.12702

White, D.J., Hubacek, K., Feng, K., Sun, L., Meng, B., 2018. The Water-Energy-Food Nexus in East Asia: A tele-connected value chain analysis using inter-regional input-output analysis. Appl. Energy 210, 550-567. https://doi.org/10.1016/j.apenergy.2017.05.159 